\title{
1 Improving food security in Asia through consumer-focused rice breeding
}

2 Marie Claire Custodio*, Matty Demont, Alice Laborte and Jhoanne Ynion

3 International Rice Research Institute (IRRI), Los Baños, Laguna, Philippines

$4 \quad *$ Corresponding author. Tel.: +63 25805600; fax: +63 25805699.

5 E-mail address: m.custodio@irri.org (M.C. Custodio).

6 Abstract

7 Public rice breeding plays a crucial role in food security in Asia, but it is often supply-focused.

8 Consumer-focused rice breeding incorporates consumer preferences in varietal development and

9 benefits (i) consumers by fostering availability of affordable rice with characteristics that meet

10 their food preferences, and (ii) farmers by facilitating market access and enabling them to

11 capture consumer surplus. We review historical evidence and survey urban consumers across 24

12 cities in seven Asian countries to assess heterogeneity and trends of consumer preferences for

13 intrinsic attributes of rice. We conclude that to improve food security in Asia, public rice

14 breeding programs should incorporate widely preferred attributes such as softness in Southeast

15 Asia and slenderness in South Asia, while considering geographic heterogeneity and specificity

16 of preferences.

17 Keywords:

18 Consumer preferences

19 Preference matching

20 Grain quality

21 Quality attributes

$22 \quad$ Value chain upgrading

23 Targeted rice breeding 


\section{Introduction}

25 Since the seventies, the concept of food security has evolved from a predominant focus on

26 supply to a multi-dimensional construct. The initial focus, reflecting the global concerns of 1974,

27 was on the volume and stability of food supplies. Food security was defined in the 1974 World

28 Food Summit as "availability at all times of adequate world food supplies of basic foodstuffs to

29 sustain a steady expansion of food consumption and to offset fluctuations in production and

30 prices" (FAO, 1996). Twenty years later, food security was defined to "exist(s) when people, at

31 all times, have physical, social or economic access to sufficient, safe and nutritious food which

32 meets their dietary needs and food preferences for an active and healthy life" (FAO, 1996).

In this article, we focus on "preference-matching" as a component of food security and

34 define it as "physical and economic access to a diversity of food options that enables consumers

35 to match their food choice to their preferences." We limit our study to intrinsic attributes or grain

36 quality that can be upgraded and tailored to urban consumers through rice breeding. Attributes

37 are product characteristics which can be classified as intrinsic or extrinsic. Color, cleanliness,

38 purity, grain shape and size, grain homogeneity (i.e. uniformity in size, shape, head rice

39 recovery), aroma, taste, and volume expansion are examples of intrinsic attributes of rice while

40 packaging, labeling, branding, reputation and information are extrinsic attributes (Demont and

41 Ndour, 2014).

The importance of preference-matching in a food security context is best understood by

43 looking at situations in which access to diversity is denied, e.g. in the case of import bans. In

44 South Korea, for example, a desire to achieve national food self-sufficiency in the 1970s led the

45 government to ban rice imports and impose on farmers the involuntary adoption of Tong-il rice, a

46 high yielding hybrid with inferior sensory characteristics compared to traditional varieties (Kim 
47 and Sumner, 2005). Although this policy helped the country in achieving self-sufficiency by

48 1976, it came at the expense of consumers, who were denied access to varieties with sensory

49 attributes that matched their preferences. After political power turn-over in 1980, planting of

50 Tong-il was eventually discontinued due to a lack of effective consumer demand.

51 This example illustrates the role of physical access to consumers' preferred food as a

52 component of food security. But even when consumers are physically able to access their

53 preferred food, their economic access may be hampered if the food is too expensive and they

54 cannot afford it. For example, governments may invest in the development and affordability of

55 food crops with higher productivity that do not necessarily match consumer preferences, while

56 underinvesting in "orphan" crops or food with certain quality characteristics valued by

57 consumers. Therefore, consumer preferences should be considered in policy efforts to increase

58 food security; otherwise these may turn out to be unsustainable.

59 Public rice breeding has mostly focused on sufficiency of supply, which may have

60 constrained varietal adoption by farmers and impact on their livelihood (Baroña-Edra, 2013),

61 probably due to the initial emphasis of food security in addressing supply constraints. But the

62 definition has evolved and this should be reflected in the goals and priorities in public rice

63 breeding, which is at the basis of food security in many rice consuming countries in Asia.

64 Therefore, preference-matching has become a crucial ingredient in the new breeding approach of

65 the International Rice Research Institute (IRRI) (Baroña-Edra, 2013) and in strategies for rice

66 value chain upgrading (Demont and Ndour, 2015). Better targeting of varieties to consumers

67 allows better optimization of use of limited breeding funds by developing varieties that more

68 effectively increase farmers' livelihood and hence reducing resources spent on varieties with less 
69 likelihood of adoption due to lack of demand and price discounts. Such endeavor entails

70 incorporating consumer preferences on a broad scale, market segments and dynamics.

71 Evaluating consumer preferences is not without challenges. A recent assessment of

72 preferred rice quality characteristics conducted by grain quality experts across the world, for

73 example, uncovered a large diversity and specificity of consumer preferences, identifying at least

7418 unique quality trait combinations of physical and biochemical characteristics (Calingacion et

75 al., 2014). In this article, we combine historical evidence from the literature with new evidence

76 from a multi-country survey conducted in major urban zones to unravel trends in consumer

77 preferences for intrinsic attributes of rice to support rice breeding priorities in selected countries

78 in Southeast Asia (Philippines, Indonesia, Thailand, Vietnam, and Cambodia) and South Asia

79 (Bangladesh and India).

Urban consumers in Asia spend more on food than rural consumers due to higher income

81 (Reardon and Timmer, 2014) and given rapid urbanization trends currently occurring in Asia,

82 urban consumption zones provide important market opportunities for rice farmers to tap into if

83 they manage to get the quality right.

\section{2. Historical trends in consumer preferences}

85 We review global, regional and national studies on consumer preferences for rice conducted in 86 selected countries in Southeast Asia (SEA) and South Asia (SA) throughout three decades

87 (Unnevehr, 1986; several chapters in Unnevehr et al., 1992a; Juliano and Villareal, 1993;

88 Rachmat et al., 2006; Calingacion et al., 2014; Hossain et al., 2015). Different sampling schemes

89 and methods in data collection were used in these studies. Hedonic price analysis was mostly

90 conducted to analyze determinants of price under the assumption that preferences for rice quality

91 are revealed by consumers through the price premiums they pay for rice with the desired 
92 characteristics (Unnevehr et al., 1992a). The study by Calingacion et al. (2014) was based on

93 experts' assessment of preferred rice varieties in each country.

94 Table 1 summarizes historical trends in consumers' preferred rice characteristics in the

95 aforementioned countries. The studies reveal that consumer preferences for rice are characterized

96 by geographic heterogeneity and specificity and are changing over time. Studies in the 1980s

97 suggest that consumers tended to focus on head rice recovery as an important quality

98 characteristic in most countries, particularly in the Philippines, Indonesia and Thailand. Due to

99 upgrading of milling technology and operations, head rice recovery has dramatically increased in

100 Asia since the eighties (Barker et al., 1985), such that many consumers now consider high head

101 rice recovery as a minimal standard and that presence of broken grains is penalized with lower

102 price (Cuevas et al., 2016). Since then, consumers have shifted their attention towards cooking

103 quality, and size and shape of the grain (Calingacion et al., 2014).

104 Size is measured by grain length and classified as short, medium, long and extra-long.

105 Shape is the ratio of grain length to width and classified as bold, medium, and slender. Texture,

106 which influences cooking and eating quality (Juliano and Villareal, 1993), can be measured

107 through apparent amylose content (AC). Rice can be classified as high, intermediate and low

108 AC. High AC rice (25-30\%) tends to cook firm and dry; rice with intermediate AC (20-25\%)

109 tends to be softer and stickier; and rice with low $\mathrm{AC}(<20 \%)$ is generally quite soft and sticky

110 (terminology adopted from IRRI's Rice Knowledge Bank). Sticky or waxy rice has zero AC.

111 Consumer preferences are greatly affected by the balance of trade of a country. Importing

112 countries, particularly urban consumers in cities close to the port and remote from rice

113 production zones, tend to develop preferences for the characteristics of imported rice (Demont

114 and Ndour, 2015). Thailand, the dominant exporter in the SEA region, plays a prominent role in 
115 this respect. Thai consumers prefer long-slender grains and aromatic rice, i.e. characteristics of

116 Jasmine rice. However, preferred texture of rice varies by region, with preference for sticky or

117 waxy rice in the North and Northeastern part of Thailand, and rice that is less sticky in the

118 Central plains. Since Thailand has established itself as an international market leader in high-

119 quality, fragrant rice, no evidence is found for a shift in consumer preferences domestically, but

120 historical trends (Table 1) seem to suggest that its exports have profoundly influenced consumer

121 preferences in other SEA countries. In the Philippines, Indonesia, Vietnam, and Cambodia,

122 consumer preferences have converged towards rice with long-slender grains and with aroma.

123 Although geographic heterogeneity is observed for texture, particularly in Indonesia and

124 Vietnam, consumers in SEA mostly prefer rice which tends to be softer and stickier when

125 cooked.

126 Cambodia and Vietnam are currently upgrading their export sectors to respond to these

127 converging consumer preferences. Cambodia has ambitions to become a major player on the

128 international market of high-quality fragrant rice (ACI, 2002; ADB, 2012; Baldwin et al., 2012).

129 Although Vietnam has been a successful exporter of non-fragrant low and medium-quality rice

130 since the eighties, it is currently restructuring and upgrading its export sector to compete with

131 Thailand in the export of high-quality rice (World Bank, 2012). Due to increasing exposure to

132 unofficial exports of Cambodian and Thai Jasmine rice through the Cambodian border (ACI,

133 2002; ADB, 2012; Baldwin et al., 2012) and rising incomes, domestic consumer preferences

134 have undergone a similar trend over the last twenty years. Recent evidence suggests geographic

135 heterogeneity in preferred texture, though; consumers in South Vietnam prefer rice with low AC

136 while in other regions rice with intermediate AC is preferred (Calingacion et al., 2014). 
The cases of Indonesia and the Philippines highlight the dynamic nature and specificity

138 of consumer preferences. Being exposed to massive rice imports from Vietnam and Thailand

139 (Baldwin et al., 2012), urban Filipino rice consumers generally prefer rice that tends to be softer

140 and stickier. Preferences for size and shape have gradually evolved from short grains in the

141 1980s - characteristic of traditional varieties at that time - to medium-size and medium-shaped

142 grains in the 1990s, and long-slender grains in the 2010s (Abansi et al., 1992; Juliano and

143 Villareal, 1993; Calingacion et al., 2014). The observable shift in preference for grain shape and

144 texture is consistent with farmers' adoption of modern rice varieties with these characteristics

145 (Laborte et al., 2015). To further illustrate the specificity of preferences in the Philippines,

146 Cuevas et al. (2016) reported that consumer preferences for grain quality characteristics (e.g.

147 head rice recovery) vary by income classes, albeit in a rural setting. In Indonesia, Juliano and

148 Villareal (1993) indicated that Javanese consumers prefer smooth with soft and sticky texture

149 while consumers in West and North Sumatra prefer rice which easily separates and tends to cook

150 firm and dry. Preferences for size and shape have likewise evolved in the 1980s-1990s

151 (Unnevehr, 1986; Juliano and Villareal, 1993) to slender grains (Rachmat et al., 2006;

152 Calingacion et al., 2014). In both countries, the recent appearance of fragrance as a preferred

153 attribute of consumers (Calingacion et al., 2014) is consistent with the trends "exported" by other

154 SEA countries.

155 In SA, demand for parboiled rice is high. Choudhury et al. (1991) argue that the most

156 preferred grain quality characteristics which drive consumer preferences towards parboiled rice

157 are head rice recovery, translucency, and hardness of cooked rice. As a consequence, consumers

158 in India and Bangladesh generally prefer rice with high AC or rice which tends to cook firm and 159 dry. A study among farming households in Bangladesh further revealed that parboiled rice is 
160 generally consumed because of its digestibility, longevity (does not easily spoil), unstickiness

161 and tastiness (Jaim and Hossain, 2012). Within India, significant regional heterogeneity of

162 consumer preferences differentiated according to grain size, shape and texture is observed, while

163 preference for characteristics of Basmati rice is evident in Punjab and Haryana states, i.e. extra-

164 long grains and aromatic (Calingacion et al., 2014). Rural consumers in East India generally

165 prefer short, bold grains, particularly the poorer households and those involved in agricultural

166 work (Bagchi et al., 2012). This rice type, which is consumed as water rice or as plain rice,

167 makes them feel full which allows them to endure long working hours on the farm. In

168 Bangladesh, preferences have shifted in the last twenty years from short-size-medium-shaped to

169 finer, slender grains (Juliano and Villareal, 1993; Calingacion et al., 2014; Hossain et al., 2015).

170 Even among rural consumers, slenderness is considered an important characteristic of rice for 171 consumption (Jaim and Hossain, 2012).

172 The results of these past studies highlight the importance of keeping in tune with the 173 evolving needs and specificity of consumer preferences for better targeting of varieties to 174 markets. Following the indicative trends from past studies, an extensive research of consumer 175 preferences and segments in the urban market following a consistent approach is an important 176 next step towards targeted rice breeding.

\section{3. Geographic segmentation of consumer preferences}

178 We review evidence from multi-country stated-preference surveys of urban rice consumers in SA 179 and SEA to further deepen our understanding on geographic segmentation of preferences for 180 intrinsic grain quality attributes and generate empirical evidence for supporting research 181 priorities for targeted rice breeding. 


\subsection{Data collection and sampling}

183 Door-to-door, face-to-face interview surveys were conducted in 24 key urban cities in seven 184 countries from May 2013 to January 2014. Multi-stage sampling was used in all countries.

185 Stratified sampling was first employed followed by random selection of primary sampling units

186 (PSU) within each stratum. Households were then selected within PSU using systematic 187 sampling by locating a starting point (e.g. village hall) and following the right hand rule from the 188 starting point and after every successful interview until the target number of interviews from 189 each starting point was achieved.

190 Target respondents included males and females between 18 and 64 years old from 191 different socio-economic classes (SEC). SEC, as an indicator of household's affluence level, is 192 country-specific. It is a spectrum whereby a household will fall into one of the classes A, B, C, D 193 or E with SEC A as the most affluent and SEC E on the other end of the spectrum. Target 194 respondents should be involved in grocery decision-making and in cooking or preparing meals 195 for the household. With this criterion, majority of respondents (90\%) were females. Respondents 196 were interviewed using a structured questionnaire translated in the local languages. Spontaneous 197 and aided types of questions were asked to elicit information. Visual stimuli were used for aided 198 questions. In the preference elicitation question, a photo card was used to verify responses 199 pertaining to grain size and shape to have a common reference point among respondents and 200 increase comparability of results. The response options for grain size were short, medium and 201 long to extra-long grains. The response options for shape were slender, medium and bold grains. 202 Respondents who mentioned aroma were also asked to describe the fragrance that they prefer to 203 further elicit aroma descriptors. 


\subsection{Data analysis}

205 Data were weighted to account for the SEC distribution and population size of each city. With 206 this, bias arising from distorted sample distribution was reduced. In the analysis, data for South 207 and East India were interpreted separately because India is a huge and diverse country. Hence, in 208 the following analysis we distinguish between eight locations, i.e. seven countries plus two 209 regions in India.

210 We assess similarity or dissimilarity of consumers' preferences in the eight locations

211 through Multiple Correspondence Analysis (MCA) (Hair et al., 2009; Macik et al., 2013).

212 Respondents were asked to describe which they consider as the most, second most and third most

213 important. A total of 101 descriptors of rice characteristics were obtained, which were then

214 categorized into 12 dichotomous rice trait variables summarized in Table 2. Per respondent, the

215 trait variables capture whether a trait has been mentioned among the three most preferred traits

216 or not. We then generate perceptual maps, where symbols with labels represent the mentioned

217 traits and locations, while dots without labels represent non-mentioned traits (Fig. 1 and 2).

218 Total variance is decomposed in MCA to arrive at a lower-dimensional representation of 219 the variables that enables reconstructing most of the variance/covariance matrix of the variables 220 (StatSoft, 2015). Inertia was also calculated to determine the amount of explained variance for 221 each dimension. In our analysis, two-dimensional perceptual maps showed that Dimension 1 ( $x$ 222 axis) has 0.15 inertia and explains $57 \%$ of the variance while Dimension 2 ( $y$-axis) has 0.11

223 inertia and explains $43 \%$ of the variance. The association between groups of consumers in 224 different locations and rice traits was assessed by examining the standardized residual and 225 verified by frequency distribution of mentions of preferred rice characteristics. A positive 226 standardized residual indicates that the observed frequency is above the expected frequency 
227 which contributes to the chi-square value hence denoting greater association between trait and

228 location. Additionally, the discrimination measure or squared correlation was calculated to

229 determine the reference dimension of each trait. It indicates the contribution of each trait to the

230 explained variance.

231 The perceptual map discriminates and identifies rice traits that have a strong association

232 towards a particular location, indicating similarity or dissimilarity with respect to the 12 traits.

233 Proximity of locations on the perceptual map indicates similarity, while proximity of locations

234 and traits indicate strong association, but it does not necessarily mean non-preference of

235 consumers from other locations.

236 Finally, in order to assess location-specificity of preferred rice characteristics by

237 consumers, we follow a procedure originally proposed by Rensis Likert for generating summated

238 scales for preference ranking (Smith and Albaum, 2005). Each respondent was asked to mention

239 the most, second most and third most important rice characteristic, which were attributed a

240 numerical weight of 3, 2, and 1, respectively. Each rice characteristic's total-importance score

241 was generated by the algebraic summation of the weights. The list of rice characteristics was

242 then ranked from highest to lowest and the top five rice characteristics with highest total score

243 were observed as the top most important rice characteristics in a specific location (Table 3).

\section{3.3. Results and discussion}

245 3.3.1. Geographic homogeneity and variability of consumers' preferred rice traits

246 Fig. 1 shows the perceptual map of the 12 rice traits and groups of consumers by region (SA and

247 SEA). The horizontal axis is the reference dimension for aroma, texture, volume expansion, 248 grain homogeneity, size, and shape while the vertical axis is the reference dimension for taste, 249 color, nutritional benefits, and ease of cooking. Purity of grains and other traits have very low 
250 contribution in explaining the variance in either dimension. This may indicate that, similar to

251 head rice recovery, consumers now take rice purity for granted thanks to widespread upgrading

252 of milling technology and post-milling operations in Asia, such that grain purity has become a

253 minimal standard, generalized for all quality classes. Horizontal proximity of traits and location

254 suggests stronger association with aroma, texture, volume expansion, grain homogeneity, size,

255 and shape, while vertical proximity suggests stronger association with taste, color, nutritional 256 benefits, and ease of cooking.

257 The perceptual map suggests that urban consumers in SEA tend to prefer rice based on its 258 texture, color, aroma, volume expansion and grain homogeneity. Preferences for rice with high

259 volume expansion and grain homogeneity are more distinct among consumers in SEA.

260 Consumers in SA, on the other hand, tend to prefer rice based on shape, size, taste, nutritional

261 benefits, and ease of cooking. Parboiling is important in this region and mineral enrichment is

262 one of the nutritional benefits of parboiling (Heinemann et al., 2005). The perceptual map

263 likewise indicates that consumers in both regions tend to prefer rice based on appearance and

264 cooking quality but they look at different aspects; SEA consumers tend to prefer rice based on

265 color and grain homogeneity while SA consumers tend to prefer rice based on shape and size of

266 the grain. With regards to cooking quality, consumers in SEA have stronger association towards

267 volume expansion (swelling capacity) while consumers in SA have stronger association towards 268 ease of cooking.

269 Fig. 2 illustrates association of the rice traits to specific countries. For simplicity, the 270 interpretation will focus on the rice traits that consumers in the region have strong association 271 with. Texture is important in SEA since consumers in all five countries tend to prefer rice based 272 on this trait. Almost the same can be observed for aroma except that consumers in the 
273 Philippines, Thailand, Cambodia, and Vietnam have stronger association towards it relative to

274 consumers in Indonesia. Tendency to prefer rice based on color (i.e. whiteness) is more

275 pronounced in the Philippines and Indonesia than in Thailand, Cambodia, and Vietnam.

276 Furthermore, urban consumers in the Philippines and Thailand share a strong association towards

277 volume expansion and grain homogeneity.

278 In SA, grain size and shape are important because consumers in all three locations tend to 279 prefer rice based on these traits. Consumers in Bangladesh and South India have stronger 280 association towards taste of rice than those in East India. Consumers in Bangladesh and East 281 India have stronger association towards ease of cooking (i.e. does not take a long time to cook 282 and does not need excessive amount of water to cook) than those in South India.

\section{3.3.2. Specificity of consumers' preferred rice characteristics}

284 The most preferred rice characteristics of consumers are summarized in Table 3. In SEA, MCA 285 suggests strong association with texture (Fig. 1), and preference ranking indicates that consumers 286 have shared preference for soft texture of rice (Table 3). Next to softness, preference for other 287 textural characteristics is likewise observed. For example, consumers in Indonesia prefer a 288 specific texture nasinya pulen, which is a local term to describe a texture as combination of 289 softness, chewiness, and unstickiness. In Vietnam, consumers in Ho Chi Minh City (HCMC) and 290 Hanoi have shared preference for sticky and chewy texture, but consumers in HCMC also prefer 291 rice which is described as "not too sticky and not too loose." In Cambodia, consumers in Phnom 292 Penh prefer rice with firm texture. This may imply either (i) a second market segment exists in 293 these cities or (ii) "softness" comes in varying degrees. The specificity of preferred texture also 294 supports the findings of Calingacion et al. (2014). They reported that AC classes of popular rice 295 varieties range low, intermediate, and high and there are variations within each AC class. For 
296 instance, low AC varieties from Thailand and Cambodia are in the lower range (i.e. 12-15\%)

297 while low AC varieties from Japan, China and Korea are in the higher range (i.e. 18-19\%). The 298 same variation within class was observed for intermediate and high AC varieties.

299 Aromatic rice is an important market for all five countries in SEA (Table 3 and Fig. 3).

300 Preference for aromatic rice cuts across SECs in all countries (Table 4). While this may suggest a

301 general trend, consumers in different countries have different descriptors of their preferred 302 fragrance. In Philippines and Indonesia, consumers describe their preferred aromatic rice to have 303 pandan scent. In Thailand, consumers in different cities have different descriptions - "sweet" in 304 Greater Bangkok and Chiang Mai and "newly harvest" in Khon Kaen.

305 Consistent with the MCA results, rice with high volume expansion is likewise an 306 important market in the Philippines and Thailand (Table 3). In the Philippines, it is preferred by 307 consumers in the middle and lower SECs, where it might be seen as a more economical way of 308 feeding the family. In Thailand, high volume expansion is preferred by consumers in all SECs.

309 This characteristic is related to general preference for aged rice or grains stored for at least two 310 years, especially for "white rice" or non-aromatic rice with long and slender grains. Older grains 311 feature more volume expansion.

312 MCA suggests that consumers in SEA do not have strong association towards size and 313 shape relative to consumers in SA; it does not necessarily mean non-preference for these traits.

314 In preference ranking analysis, among respondents in SEA who consider size a preferred trait, 315 majority prefer long to extra-long grains. Among respondents who consider shape as a preferred 316 trait, nearly half prefer slender grains followed by medium-shaped grains.

317 In SA, where consumers have strong association towards grain size and shape, preference 318 for slender grains largely dominates preference for medium and bold shape (Fig. 4, upper graph). 
319 On the other hand, preference for grain size is highly differentiated across countries and even

320 across cities (Fig. 4, lower graph). The specificity of preference for grain size was observed

321 across SECs in Bangladesh where preference for long to extra-long grains is higher as one moves

322 to higher socio-economic classes at the expense of medium and short grains. Preference for

323 specific grain size may be derived from consumers' popular rice dishes. In Bangladesh, for

324 instance, short grains are preferred in making Payesh, a milk-based sweet rice pudding. In East

325 India, medium-sized grains are preferred for pulav/pulao and vegetable fried rice. Further

326 evaluating the interaction of size and shape, we observed three dominant classes or size-shape

327 combinations preferred by consumers in the three locations in SA. These are short-slender,

328 medium-slender, and long-slender. Medium-medium (size and shape) is also an important class

329 for consumers in both East and South India.

330 Aromatic rice is also an important market in SA (Table 3 and Fig. 3) but with more

331 specific markets, particularly in East India where demand is mainly coming from Kolkata and

332 Patna. Differentiated demand is observed towards nutritional benefits, with urban consumers in

333 Chittagong (Bangladesh) preferring rice with vitamin content, suggesting the existence of a

334 nutrition-sensitive market segment particularly among parboiled-rice consumers. In the three

335 cities surveyed in Bangladesh, it is in Chittagong where nutritional benefit is considered as an

336 important characteristic by parboiled-rice consumers relative to non-parboiled-rice consumers.

337 MCA suggests that consumers in SA do not have strong association towards texture but it

338 is widely known that high AC rice (i.e. rice tends to cook firm and dry) is generally preferred as

339 reflected by their consumption of parboiled rice. But perhaps due to wide preference for it, not

340 much emphasis was given by respondents when asked in general context, i.e. it was taken for

341 granted by many consumers. Preference ranking analysis suggests differentiated demand for 
342 sticky rice in Khulna (Bangladesh). Two points can be hypothesized. First, sticky rice may be

343 used in making certain rice dishes for special occasions since there are local varieties grown in

344 coastal areas which are slightly sticky and could have been made available to consumers in the

345 city. Second, consumers may be referring to non-parboiled ("raw") rice, which is emerging in the

346 country. In East India, preference for rice characteristics pertaining to texture was observed only

347 in two cities, i.e. smoothness and softness in Guwahati and softness in Dhanbad. In South India, 348 consumers prefer smooth texture of rice.

\section{4. Conclusions and implications for rice breeding}

350 Historical evidence and urban consumer surveys reveal that over the last thirty years, SEA rice

351 consumers have gradually converged towards a shared preference for fragrant rice with soft

352 texture (intermediate AC). This trend towards "Jasminization" of consumer preferences is

353 probably induced by first movers like Thailand. Its establishment as a market leader in the export

354 of high-quality, fragrant Jasmine rice has profoundly shaped consumer preferences in importing

355 (Philippines and Indonesia) and second-mover SEA countries (Cambodia and Vietnam). Due to

356 fast urbanization, rising incomes and the entry of second-mover competitors, it is expected that

357 this trend will be maintained for some time as supply of high-quality, fragrant rice expands and

358 becomes affordable to a larger population with preferences for fragrance cutting across SECs.

359 Therefore, forward-looking rice breeding programs should invest in these widely preferred traits

360 and incorporate them into their varietal development programs. Moreover, given the importance

361 attributed by importing countries like Indonesia and the Philippines to achieving self-sufficiency

362 (Baldwin et al., 2012), rice breeders will have to upgrade domestic rice varieties to "imported"

363 preference standards (e.g. soft texture and fragrance) to help domestic farmers competing

364 quality-wise against imports in urban markets (Demont, 2013; Demont and Ndour, 2015). 
However, in line with experts' assessment, variations in descriptors of texture were found

366 which point to the existence of market segments that further differentiate rice texture within the

367 intermediate AC class. Similarly for aroma, our study supports the experts' (Calingacion et al.,

368 2014) conclusion that aside from 2-acetyl-1-pyrroline, other compounds and fragrance

369 descriptors may need to be explored to satisfy differentiated demand for rice fragrance. This

370 highlights the need for texture and aroma profiling in breeding programs to identify specific

371 chemical properties needed to quantify the descriptors provided by consumers. Following our

372 research, the next step is to translate these findings, especially the "subjective" descriptors to

373 "objectively" measured grain quality parameters that can be used by breeders. Indicative results

374 from grain quality evaluation of few market samples purchased in the Philippines further justify

375 this recommendation; Sinandomeng and Angelica have high AC and Jasmine has low AC. But

376 despite different classes, consumers consider both as having soft texture.

377 In the Philippines and Thailand, volume expansion and grain homogeneity should be 378 prioritized in product profile development. In the 1980s, consumers' emphasis in the Philippines,

379 Indonesia and Thailand was on greater head rice recovery, but our urban survey indicates that

380 this preference has evolved towards grain homogeneity, which includes head rice recovery and 381 uniformity of grain size and shape. The latter can be enhanced through upgrading of milling 382 operations (separation of varieties, sorting and grading), while the former can be improved partly 383 through upgrading of milling equipment and partly through rice breeding (IRRI, 2015).

Although SEA consumers did not show positive association towards grain size and shape 385 relative to those in SA, preference ranking suggests that among consumers who consider these as 386 preferred trait, long to extra-long and slender grains are preferred. 
In SA, the observable shift in preference for slender grains and varying preference for grain sizes reported in the past studies are validated by our urban consumer surveys. Preference

389 for slender grains is widely shared across countries, cities and SECs, which suggests that rice 390 breeding programs in SA should place high priority on this trait. Preference for grain size, on the 391 other hand, is highly heterogeneous across locations and SECs. The location-specificity may be 392 due to the diverse and huge geography of India and diversity of rice dishes in SA. Our findings 393 suggest three major classes of size-shape combinations preferred by consumers in SA, i.e. short394 slender, medium-slender, and long-slender. Medium-medium is also an important class for 395 consumers in both East and South India. Rice breeding programs should account for this 396 geographical heterogeneity and differentiate their product profiles accordingly.

Past studies indicate a widely shared preference for rice that tends to cook firm and dry 398 (i.e. high AC), as a characteristic of parboiled rice. The current study suggests differentiated 399 demand for sticky rice in Khulna (Bangladesh), which may be linked to the emergence of non400 parboiled rice and existence of niche market for specialty dishes. Local preferences for smooth 401 and soft textures in Guwahati, East India and smooth texture in South India were likewise 402 observed. Preference for aromatic rice in SA was not evident in most studies reviewed, except 403 for Basmati-consuming regions in India. Our surveyed consumers in SA suggest its importance 404 in specific markets (i.e. Kolkata and Patna in East India). Results of the current study also 405 suggest differentiated demand for rice with nutritional benefits in Chittagong (Bangladesh), 406 which may indicate its emerging importance in the country. These findings highlight 407 opportunities for rice breeding programs to introduce specialty rice (sticky, fragrant and 408 nutritious rice) in specific markets throughout SA, which can help farmers increase their 409 livelihood by capturing consumer surplus for these traits. 
Our findings can be used by rice breeders for setting priorities and incorporating grain

411 quality improvements, which are relevant to targeted market segments, along with agronomic,

412 stress-tolerance and by-product traits, which are relevant to farmers. Quality preferences widely

413 shared in the region may provide input for regional breeding programs while local preferences

414 may be considered in the national programs to address the needs of specific markets. Another

415 way for categorizing these traits is whether they respond to demand from the market ("market-

416 smart") or to climatic conditions in the growing environment ("climate-smart"). This study

417 focuses on market-smart traits, but rice breeders should combine market and climate-smart traits

418 in optimal product profiles tailored to specific needs in production zones and the rice value

419 chains they are supplying to. If breeders fail to tailor rice varieties to consumer preferences, other

420 actors in downstream segments of the rice value chain may do so and capture consumer surplus.

421 For example, millers, wholesalers and exporters can mix varieties to provide different "grades"

422 of texture or double-polish grains to increase slenderness as what is currently done in Bangladesh

423 for the so-called "Minikit" rice. Failure to incorporate agronomic and stress-tolerance traits, on

424 the other hand, may expose farmers to higher climate and production risks. Therefore, public rice

425 breeding programs should consistently incorporate market research on consumer and farmer 426 preferences, segments and dynamics on a broad scale and repeated on a regular basis into their

427 strategic planning. In the long run, market and climate-smart rice breeding will contribute to 428 more efficient, equitable and sustainable rice value chains as a result of better linkages between 429 rice farmers and consumers.

\section{Acknowledgements}

431 Financing from the Global Rice Science Partnership (GRiSP) and Bill \& Melinda Gates 432 Foundation (BMGF) Transforming Rice Breeding (TRB) Project are greatly acknowledged. 


\section{References}

434 Abansi, C.L., Duff, B., Lantican, F.A., Juliano, B.O., 1992. Consumer demand for rice grain Cambodia.

ADB, 2012. The rice situation in Cambodia. Technical Assistance Consultant's Report, Asian

ACI, 2002. Rice value chain study: Cambodia. Agrifood Consulting International, Phnom Penh,

Development Bank

(ADB),

Manila,

Philippines.

Bagchi, B.D., Behura, D., Lakra, V., Jaim, W.M.H., Hossain, M., 2012. Consumers’ preferences (http://www.adb.org/sites/default/files/project-document/73081/43430-012-reg-tacr01.pdf).

for grain quality and rice milling and cooking practices for eastern India: Implications for nutrition. In: Hossain, M., Jaim, W.H.M., Paris, T.R., Hardy, B. (Eds.), Adoption and diffusion of modern rice varieties in Bangladesh and eastern India. Los Baños (Philippines): International Rice Research Institute, pp. 93-106.

Baldwin, K., Childs, N., Dyck, J., Hansen, J., 2012. Southeast Asia’s rice surplus. Electronic Outlook Report RCS-121-01, Economic Research Service, United States Department of Agriculture (USDA), Washington DC. (http://www.ers.usda.gov/media/978994/rcs-12101.pdf).

Barker, R., Herdt, R.W., Rose, B., 1985. The Rice Economy of Asia. Resources for the Future, Washington, D.C. 
Baroña-Edra, M.L., 2013. The pipeline grows stronger: IRRI overhauls its breeding agenda. Rice Today 12, 14-15. (http://ricetoday.irri.org/the-pipeline-grows-stronger-blank/).

Calingacion, M., Laborte, A.G., Nelson, A., Resurreccion, A., Concepcion, J.C., Daygon, V.D., et al., 2014. Diversity of global rice markets and the science required for consumer$\begin{array}{llllll}\text { targeted rice } \quad \text { breeding. } & \text { PLoS }\end{array}$ http://dx.doi.org/10.1371/journal.pone.0085106.

Chandler Jr., R.F., 1972. The impact of the improved tropical plant type on rice yields in South and Southeast Asia. In: Rice breeding. International Rice Research Institute, Los Baños (Philippines), pp. 77-85.

Choudhury, N.H., 1991. Parboiling and consumer demand for parboiled rice in South Asia. In: Rice Grain Marketing and Quality Issues. International Rice Research Institute, Manila, Philippines, pp. 47-54.

Choudhury, N., Kabir, K.A., Biswas, S.K., Islam, R., 1992. Influence of rice grain properties on market price in Bangladesh. In: Unnevehr, L.J., Duff, B., Juliano, B.O. (Eds.), Consumer Demand for Rice Grain Quality. International Rice Research Institute, Manila, Philippines, pp. 117-133.

Cuevas, R.P., Pede, V., McKinley, J., Velarde, O., Demont, M., 2016. Rice grain quality and consumer preferences: A case of two rural towns in the Philippines. PLoS ONE 11(3): e0150345. doi:10.1371/journal.pone.0150345.

Damardjati, D.S., Oka, M., 1992. Evaluation of urban consumer preferences for rice quality characteristics in Indonesia. In: Unnevehr, L.J., Duff, B., Juliano, B.O. (Eds.), Consumer Demand for Rice Grain Quality. International Rice Research Institute, Manila, Philippines, pp. 59-73. 
Demont, M., 2013. Reversing urban bias in African rice markets: a review of 19 National Rice Development Strategies. Global Food Secur. 2, 172-181. http://dx.doi.org/10.1016/j.gfs.2013.07.001.

Demont, M., Ndour, M., 2015. Upgrading rice value chains: Experimental evidence from 11 African markets. Global Food Secur. 5, 70-76. http://dx.doi.org/10.1016/j.gfs.2014.10.001.

FAO, 1996. Trade and Food Security: Conceptualizing the Linkages Expert Consultation. (http://www.fao.org/docrep/005/y4671e/y4671e06.htm\#TopOfPage). (accessed August 13, 2015).

Hair Jr., J.F., Black, W.C., Babin, B.J., Anderson, R.E., 2009. Multivariate Data Analysis. $7^{\text {th }}$ Ed. Prentice Hall, Saddle River, NJ, USA.

Heinemann, R.J.B., Fagundes, P.L., Pinto, E.A., Penteado, M.V.C., Lanfer-Marquez, U.M., 2005. Comparative study of nutrient composition of commercial brown, parboiled and milled rice from Brazil. J. Food Comp. Anal. 18, 287-296. http://dx.doi.org/10.1016/j.jfca.2004.07.005.

Hossain, M.I., Rahman, N.M.F., Kabir, M.S., Siddique, M.A.B., Tareq, M., 2015. Development and validation of producer and consumer preference models for rice varieties in Bangladesh. Bangladesh Rice J. 19(1):63 - $71, \quad 2015$. DOI: http://dx.doi.org/10.3329/brj.v19i1.25223.

International Rice Research Institute (IRRI), 2015. Rice Knowledge Bank. (http://www.knowledgebank.irri.org/ricebreedingcourse/Grain_quality.htm). （accessed 23.10.15). 
Jaim, W.M.H., Hossain, M., 2012. Rice milling processes, consumers' preferences and cooking practices in Bangladesh: Implications for nutritional value. In: Hossain, M., Jaim, W.H.M., Paris, T.R., Hardy, B. (Eds.), Adoption and diffusion of modern rice varieties in Bangladesh and eastern India. Los Baños (Philippines): International Rice Research Institute, pp. $77-92$.

Juliano, B.O., Villareal, C.P., 1993. Grain Quality Evaluation of World Rices. International Rice Research Institute, Manila, Philippines.

pp. $12-34$.

508 509 (http://books.irri.org/9712200396_content.pdf).

Khush, G.S., Virk, P.S., 2005. IR varieties and their impact. Los Baños (Philippines): International Rice Research Institute. 163p.

Khush, G.S., Coffman, W.R., Beachell, H.M., 2001. The history of rice breeding: IRRI's contribution. In: Rockwood, W.G. (Ed.), Rice research and production in the $21^{\text {st }}$ century: Symposium Honoring Robert F. Chandler, Jr., International Rice Research Institute, Los Baños (Philippines), pp. $117-135$.

Kim, Y.-S., Sumner, D.A., 2005. Measuring research benefits with import ban restrictions, quality changes, non-market influences on adoption and food security incentives. In: Proceedings of the American Association of Agricultural Economists Annual Meeting, Providence, Rhode Island, 24-27 July 2005. (http://purl.umn.edu/19148).

Laborte, A.G., Paguirigan, N.C., Moya, P.F., Nelson, A., Sparks, A.H., Gregorio, G.B., 2015. Farmers' preference for rice traits: Insights from farm surveys in Central Luzon, Philippines, 1966-2012. PLoS ONE $10, \quad$ e0136562. http://dx.doi.org/10.1371/journal.pone.0136562. 
522 Macik, R., Macik, D., Nalewajek, M., 2013. Consumer preferences for retail format choice 523 case of polish consumers. In: Management, Knowledge and Learning International Conference, Zadar, Croatia, 19-21 June 2013. (http://www.toknowpress.net/ISBN/978-

Moya, P., Kajisa, K., Barker, R., Mohanty, S., Gascon, F., San Valentin, M.R., 2015. Changes in rice farming in the Philippines: Insights from five decades of a household-level survey. 961-6914-02-4/papers/ML13-341.pdf).

Rachmat, R., Thahir, R., Gummert, M., 2006. The empirical relationship between price and quality of rice at market level in West Java. Indones. J. Agric. Sci. 7, 27-33. (http://pustaka.litbang.pertanian.go.id/publikasi/as071065.pdf).

Reardon, R., Timmer, C.P., 2014. Five-interlinked transformations in the Asian agrifood economy: Food security implications. Global Food Secur. 3, 108-117. http://dx.doi.org/10.1016/j.gfs.2014.02.001.

Smith, S.M., Albaum, G.S., 2005. Fundamentals of Marketing Research. Sage Publications, Thousand Oaks, CA. (https://us.sagepub.com/sites/default/files/upmbinaries/4553_Smith_Chp_10.pdf).

Sriswasdilek, J., Kongseree, N., Attaviriyasook, K.. 1992. Rice grain characteristics affecting retail price in Thailand. In: Unnevehr, L.J., Duff, B., Juliano, B.O. (Eds.), Consumer Demand for Rice Grain Quality. International Rice Research Institute, Manila, Philippines, pp. 97-108.

StatSoft, 2015. Correspondence Analysis. (http://www.statsoft.com/Textbook/CorrespondenceAnalysis). (accessed 21.10.15) 
544 Unnevehr, L.J., 1986. Consumer demand for rice grain quality and returns to research for quality 545 improvement in Southeast Asia. Am. J. Agric. Econ. 68, 634-641. $546 \quad$ http://dx.doi.org/10.2307/1241547.

547 Unnevehr, L.J., Duff, B., Juliano, B.O. (Eds.), 1992a. Consumer Demand for Rice Grain Quality. International Rice Research Institute, Manila, Philippines.

550 Unnevehr, L.J., Duff, B., Juliano, B.O., 1992b. Consumer demand for rice grain quality: 551 introduction and major findings. In: Unnevehr, L.J., Duff, B., Juliano, B.O. (Eds.), 552 Consumer Demand for Rice Grain Quality. International Rice Research Institute, Manila, 553 Philippines, pp. 5-19. (http://books.irri.org/9712200302_content.pdf).

554 World Bank, 2012. Vietnam Rice, Farmers and Rural Development: from Successful Growth to 555 Sustainable Prosperity. Hanoi, Vietnam. 
Table 1

Historical trends in consumers' preferred rice characteristics in selected countries in South and Southeast Asia. $1980 \mathrm{~s}^{\mathrm{a}} \quad 1990 \mathrm{~s}^{\mathrm{b}} \quad 2000 \mathrm{~s}-2010 \mathrm{~s}^{\mathrm{c}}$

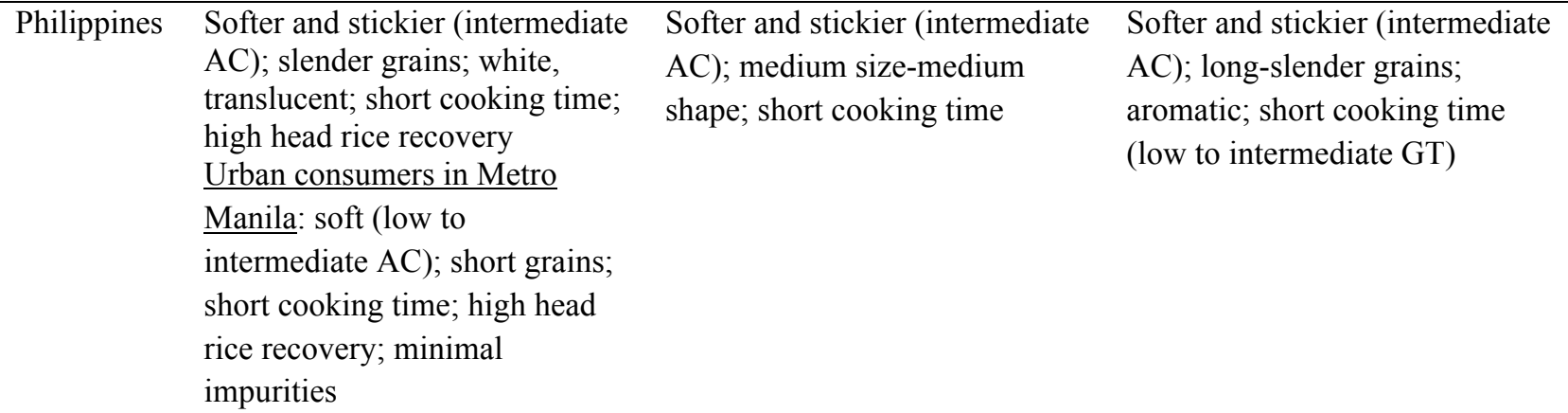

Indonesia Softer and stickier (intermediate AC); medium shape; white; short cooking time; high head rice recovery Jakarta: soft/more sticky Medan: soft Ujung Pandang: hard-cooked

Thailand Softer and stickier (intermediate AC); slender grains; white; aromatic; high head rice recovery;

Non-glutinous rice: soft (low to intermediate $\mathrm{AC}$ ); long grains; translucent grains (not chalky); aromatic; high head rice recovery; Glutinous rice: high head rice recovery

Vietnam

Cambodia

India
Java: smooth texture (pulen) with intermediate AC (softer and stickier)

West \& North Sumatra: easily separating, high AC (firm and dry) with hard texture (pera); medium size-medium shape

Long-slender grains; translucent grains

Northeast region: quite soft and sticky (low AC)

Northern region: waxy or sticky texture

Central region: softer and stickier (intermediate AC)

Softer and stickier (intermediate AC); short size-medium shape grains (traditional varieties)

Softer and sticky (intermediate AC); medium size-medium shape; short cooking time

Medium size-medium shape Basmati consuming regions: softer and stickier (intermediate AC) Other regions: firm and dry (high AC) Parboiled rice: Hard texture; translucency; high head rice
Softer and stickier (intermediate AC); medium-slender grains West Java: softer and stickier (intermediate $\mathrm{AC}$ ); long and slender grains West and Central Java: aromatic

Long-slender grains; aromatic; short cooking time North \& Northeast: waxy or sticky texture; Other regions: low to high AC (quite soft and sticky to firm and dry)

Long grains; aromatic Southern region: quite soft and sticky (low AC) Other regions: softer and stickier (intermediate AC)

Quite soft and sticky (low AC); long-slender grains; aromatic; short cooking time

Softer and stickier (intermediate $\mathrm{AC}$ ) to firm and dry (high AC); size varies by location (short, medium, extra-long); shape varies by location (mainly slender and medium-slender); Basmati in Punjab and Haryana: 
recovery

Bangladesh Parboiled rice: firm and dry

(high AC); slender; short

cooking time; high head rice

recovery
Parboiled rice: firm and dry

(high AC); short size-mediumshaped grains extra-long grains and aromatic

Firm and dry (high AC);

medium-slender grains; fine

grains

Note: The grain quality terms used are adopted from IRRI's (2015) Rice Knowledge Bank.

559 Sources:

560 a'Unnevehr (1986), Abansi et al. (1992), Choudhury et al. (1992), Damardjati and Oka (1992), Sriswasdilek et al.

$561 \quad(1992)$;

$562 \quad{ }^{b}$ Choudhury (1991), Juliano and Villareal (1993);

$563{ }^{\mathrm{c}}$ Rachmat et al. (2006), Calingacion et al. (2014), Hossain et al. (2015). 
Table 2

565 Rice trait variables and corresponding descriptors elicited from urban consumers during surveys in selected cities in 566 South and Southeast Asia in 2013-2014.

\begin{tabular}{ll}
\hline Category of traits & Rice characteristics (descriptors based on respondents' responses) \\
\hline Taste & Good taste, delicious, tasteful, sweet \\
Size & Short, medium, long to extra-long \\
Shape & Bold, medium, slender \\
Color & White, yellowish, brown, red, black, unspecified \\
Grain homogeneity & Uniform size and shape, grains not broken/whole kernels \\
Aroma & Pandan-like, sweet, newly-harvested, pure/unique rice aroma, unspecified \\
Texture & Soft, sticky, not sticky, firm, chewy, not too sticky not too loose, smooth \\
Volume expansion & High volume expansion, increase in quantity after cooking \\
Ease of cooking & Does not need excessive water, grains do not need a lot of water to cook, does not take a \\
& long time to cook, easy to cook \\
Nutritional benefits & Has high nutrition, non-fattening, contains vitamins, "whole grain" (unpolished), \\
& nutritional benefits (unspecified) \\
Purity/cleanliness & No/little impurities, clean, no unhulled rice or small, no stones, no dead rice \\
Other traits & Shiny, rice stays good for long time, does not quickly stale, good quality (unspecified) \\
\hline
\end{tabular}


Table 3

568 Top five most preferred rice characteristics based on urban consumer surveys in 24 cities in selected South and

569 Southeast Asian countries in 2013-2014.

\begin{tabular}{|c|c|c|c|c|c|c|c|c|}
\hline \multirow[b]{2}{*}{ Rank } & \multicolumn{5}{|c|}{ Southeast Asia } & \multicolumn{3}{|c|}{ South Asia } \\
\hline & Philippines & Indonesia & Thailand & Vietnam & Cambodia & $\begin{array}{l}\text { East } \\
\text { India }\end{array}$ & $\begin{array}{l}\text { South } \\
\text { India }\end{array}$ & Bangladesh \\
\hline 1 & Aromatic & White & Soft & $\begin{array}{l}\text { Sticky and } \\
\text { chewy }\end{array}$ & Soft & Slender & $\begin{array}{l}\text { Good } \\
\text { taste }\end{array}$ & Good taste \\
\hline 2 & Soft & $\begin{array}{l}\text { Nasinya } \\
\text { pulen* }\end{array}$ & Aromatic & Aromatic & Aromatic & White & White & White \\
\hline 3 & White & Aromatic & White & Soft & Good taste & $\begin{array}{l}\text { Medium- } \\
\text { size }\end{array}$ & Slender & Slender \\
\hline 4 & $\begin{array}{l}\text { High } \\
\text { volume } \\
\text { expansion }\end{array}$ & Soft & $\begin{array}{l}\text { High } \\
\text { volume } \\
\text { expansion }\end{array}$ & White & White & $\begin{array}{l}\text { Good } \\
\text { taste }\end{array}$ & $\begin{array}{l}\text { Medium- } \\
\text { size }\end{array}$ & Short \\
\hline 5 & Chewy & Good taste & $\begin{array}{l}\text { Long to } \\
\text { extra-long }\end{array}$ & $\begin{array}{l}\text { Not too } \\
\text { sticky and } \\
\text { not too } \\
\text { loose }\end{array}$ & $\begin{array}{l}\text { Firm } \\
\text { texture }\end{array}$ & Aromatic & Smooth & Aromatic \\
\hline $\mathrm{n}$ & 500 & 500 & 500 & 300 & 350 & 803 & 619 & 501 \\
\hline
\end{tabular}

570 Notes: Shape (bold, slender, medium) and size (short, medium, long to extra-long) refer to uncooked grains.

571 *Nasinya pulen is a local term in Indonesia referring to rice texture described as combination of soft, chewy, not 572 sticky. Locations: Philippines: National capital region (NCR), Cebu, Davao; Indonesia: Jakarta, Surabaya, Medan;

573 Thailand: Greater Bangkok (GBKK), Chiang Mai, Khon Kaen; Vietnam: Ho Chi Minh City, Hanoi; Cambodia:

574 Phnom Penh, Siem Reap; East India: Kolkata, Guwahati, Bhubaneshwar, Patna, Dhanbad; South India: Chennai,

575 Erode, Hyderabad; Bangladesh: Dhaka, Chittagong, Khulna 
Table 4

Aroma descriptors by location and preference by socio-economic classes based on consumer surveys in 13 cities in 578 selected Southeast Asian countries in 2013-2014.

\begin{tabular}{|c|c|c|c|c|c|}
\hline \multirow[t]{2}{*}{ Country } & \multirow[t]{2}{*}{ Aroma descriptors } & \multicolumn{4}{|c|}{ Preference for aroma by SEC } \\
\hline & & $\begin{array}{l}\text { Socio-economic class } \\
\text { (SEC) }\end{array}$ & $n$ & $\begin{array}{c}\text { Rank } \\
\text { (Aroma) }\end{array}$ & $\begin{array}{l}\text { Proportion of } \\
\text { respondents who } \\
\text { consider aroma as most } \\
\text { preferred rice trait }\end{array}$ \\
\hline \multirow[t]{4}{*}{ Philippines } & Pandan-like & $\mathrm{ABC1}$ & 34 & $2^{\text {nd }}$ & $55 \%$ \\
\hline & & $\mathrm{C} 2$ & 116 & $1^{\text {st }}$ & $73 \%$ \\
\hline & & $\mathrm{D}$ & 265 & $1^{\text {st }}$ & $71 \%$ \\
\hline & & $\mathrm{E}$ & 85 & $1^{\text {st }}$ & $72 \%$ \\
\hline \multirow[t]{4}{*}{ Indonesia } & Pandan-like & $\mathrm{AB}$ & 174 & $3^{\text {rd }}$ & $47 \%$ \\
\hline & & $\mathrm{C} 1$ & 173 & $3^{\text {rd }}$ & $33 \%$ \\
\hline & & $\mathrm{C} 2$ & 79 & $4^{\text {th }}$ & $26 \%$ \\
\hline & & $\mathrm{DE}$ & 75 & $2^{\text {nd }}$ & $34 \%$ \\
\hline \multirow{3}{*}{ Thailand } & Sweet (Greater & $\mathrm{AB}$ & 97 & $2^{\text {nd }}$ & $60 \%$ \\
\hline & Bangkok and Chiang & $\mathrm{C}$ & 239 & $2^{\text {nd }}$ & $43 \%$ \\
\hline & Mai); Newly harvest & $\mathrm{DE}$ & 163 & $3^{\text {rd }}$ & $37 \%$ \\
\hline \multirow[t]{4}{*}{ Vietnam } & Pure/unique rice aroma & A & 50 & $2^{\text {nd }}$ & $61 \%$ \\
\hline & (Ho chi minh, Hanoi); & B & 110 & $3^{\text {rd }}$ & $50 \%$ \\
\hline & Fresh harvest (Hanoi) & $\mathrm{C}$ & 107 & $1^{\text {st }}$ & $53 \%$ \\
\hline & & $\mathrm{D}$ & 32 & $3^{\text {rd }}$ & $31 \%$ \\
\hline \multirow{4}{*}{ Cambodia } & Sweet (Phnom Penh & A & 56 & $1^{\mathrm{st}}$ & $73 \%$ \\
\hline & and Siem Reap); & B & 94 & $3^{\text {rd }}$ & $67 \%$ \\
\hline & Pandan-like (Siem & $\mathrm{C}$ & 119 & $2^{\text {nd }}$ & $65 \%$ \\
\hline & Reap & $\mathrm{DE}$ & 81 & $2^{\text {nd }}$ & $58 \%$ \\
\hline
\end{tabular}

Note: SEC, as an indicator of household's affluence level, is country-specific and definitions vary in the different countries. It is a spectrum whereby a household will fall into one of the classes A, B, C, D or E with SEC A as the most affluent and SEC E on the other end of the spectrum. Locations: Philippines: National capital region (NCR), Cebu, Davao; Indonesia: Jakarta, Surabaya, Medan; Thailand: Greater Bangkok (GBKK), Chiang Mai, Khon Kaen; Vietnam: Ho Chi Minh City, Hanoi; Cambodia: Phnom Penh, Siem Reap. 


\title{
Joint Plot of Category Points
}

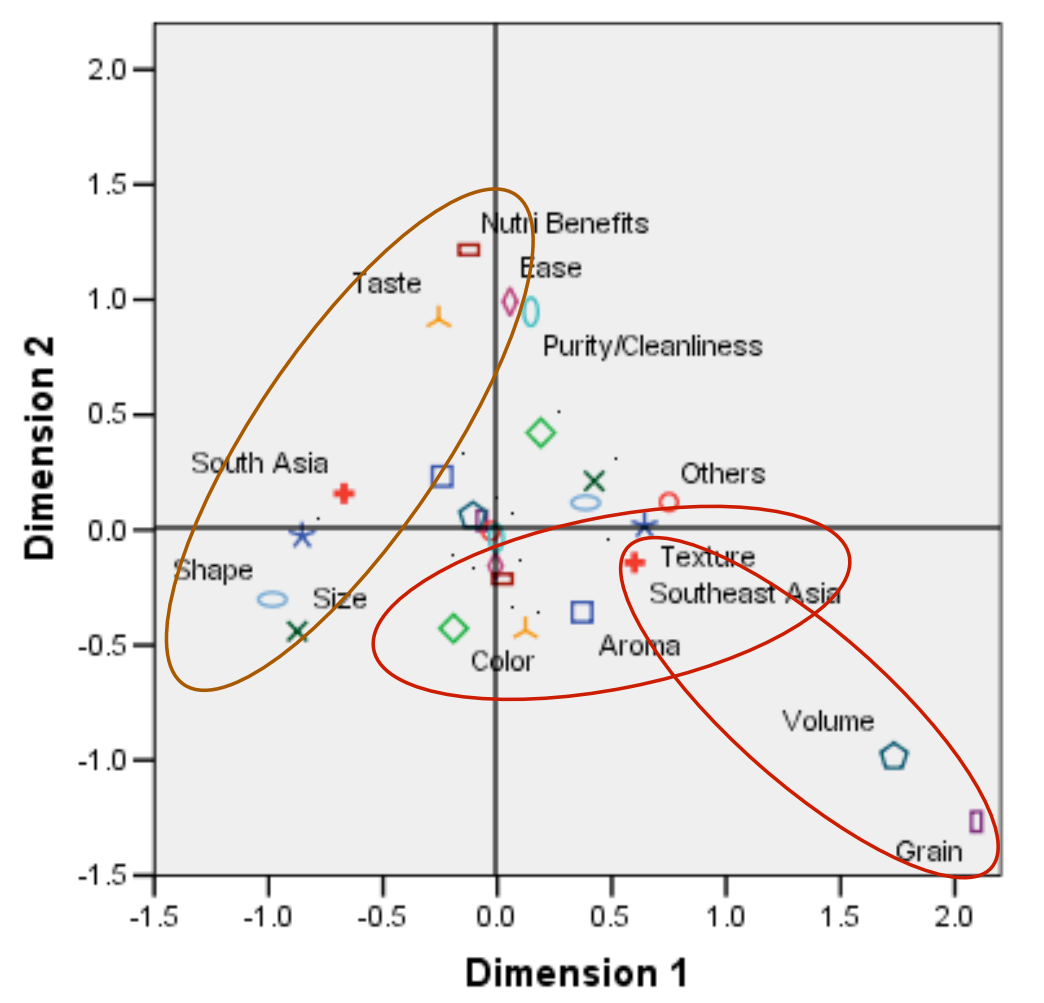

\author{
$\square$ Aroma \\ $\checkmark$ Color \\ $\Delta$ Ease of cooking \\ [ Grain Homogeneity \\ ㅁ Nutritional Benefits \\ Other Traits \\ 0 Purity/Cleanliness \\ + Region \\ Shape \\ $\times$ Size \\ ᄉ Taste \\ * Texture \\ $\triangle$ Volume Expansion
}

Dimension 1:

Inertia $=0.151$

( $57 \%$ of total)

Dimension 2:

Inertia $=0.113$

(43\% of total)

Variable Principal Normalization.

Fig. 1. Perceptual map of urban consumers' most preferred rice traits by region based on consumer surveys in 24 cities in selected South and Southeast Asian countries in 2013-2014. In this map, symbols with labels represent the most preferred rice traits while dots without labels represent the non-mentioned traits. Dimension 1 is the reference axis for aroma, texture, volume expansion, grain homogeneity, size, and shape while Dimension 2 is the reference axis for taste, color, nutritional benefits, and ease of cooking. 


\section{Joint Plot of Category Points}

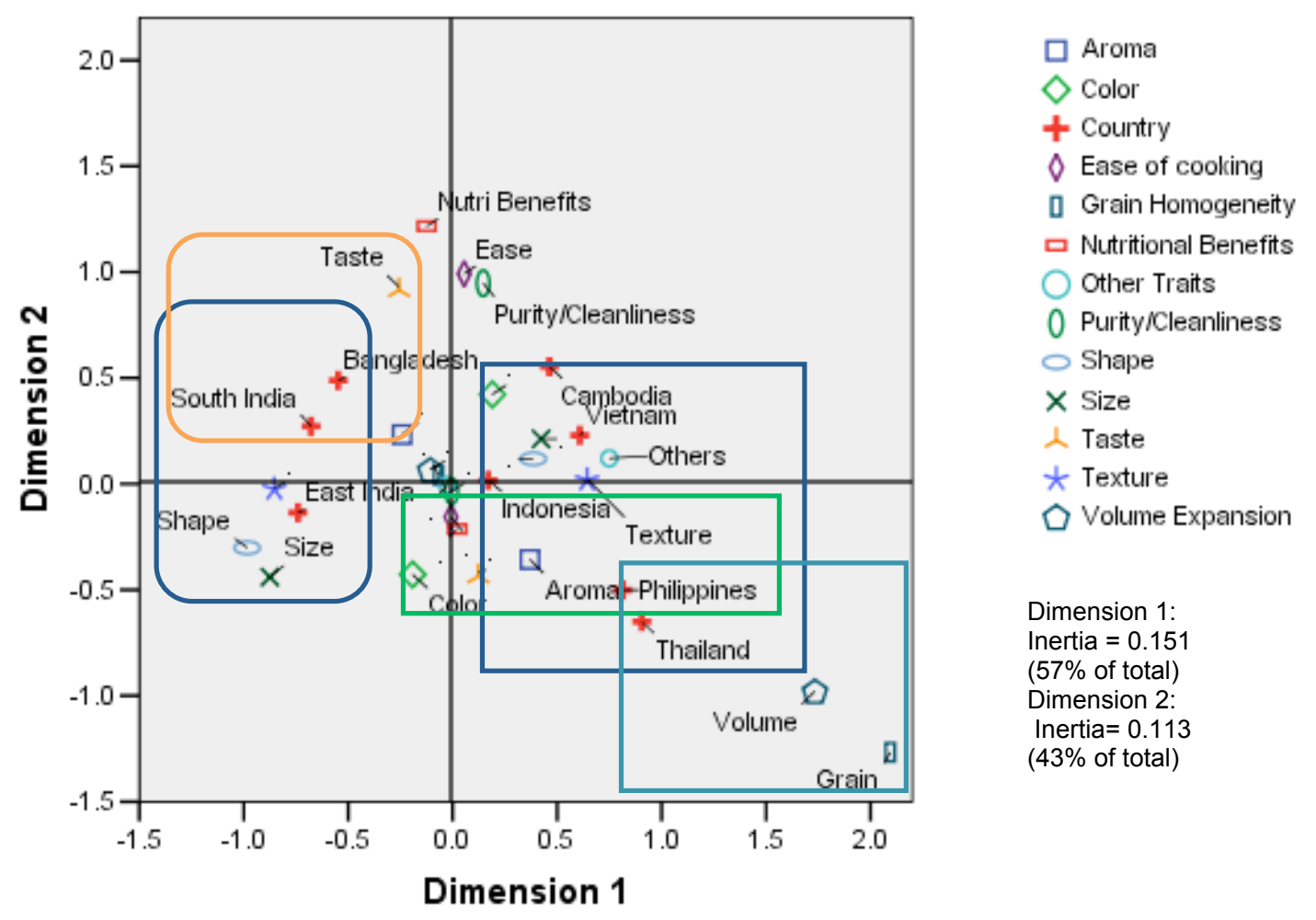

Variable Principal Normalization.

Fig. 2. Perceptual map of consumers' most preferred rice traits by country based on consumer surveys in 24 cities in selected South and Southeast Asian countries in 2013-2014. In this map, symbols with labels represent the most preferred rice traits while dots without labels represent the non-mentioned traits. Dimension 1 is the reference axis for aroma, texture, volume expansion, grain homogeneity, size, and shape while Dimension 2 is the reference axis for taste, color, nutritional benefits, and ease of cooking. 


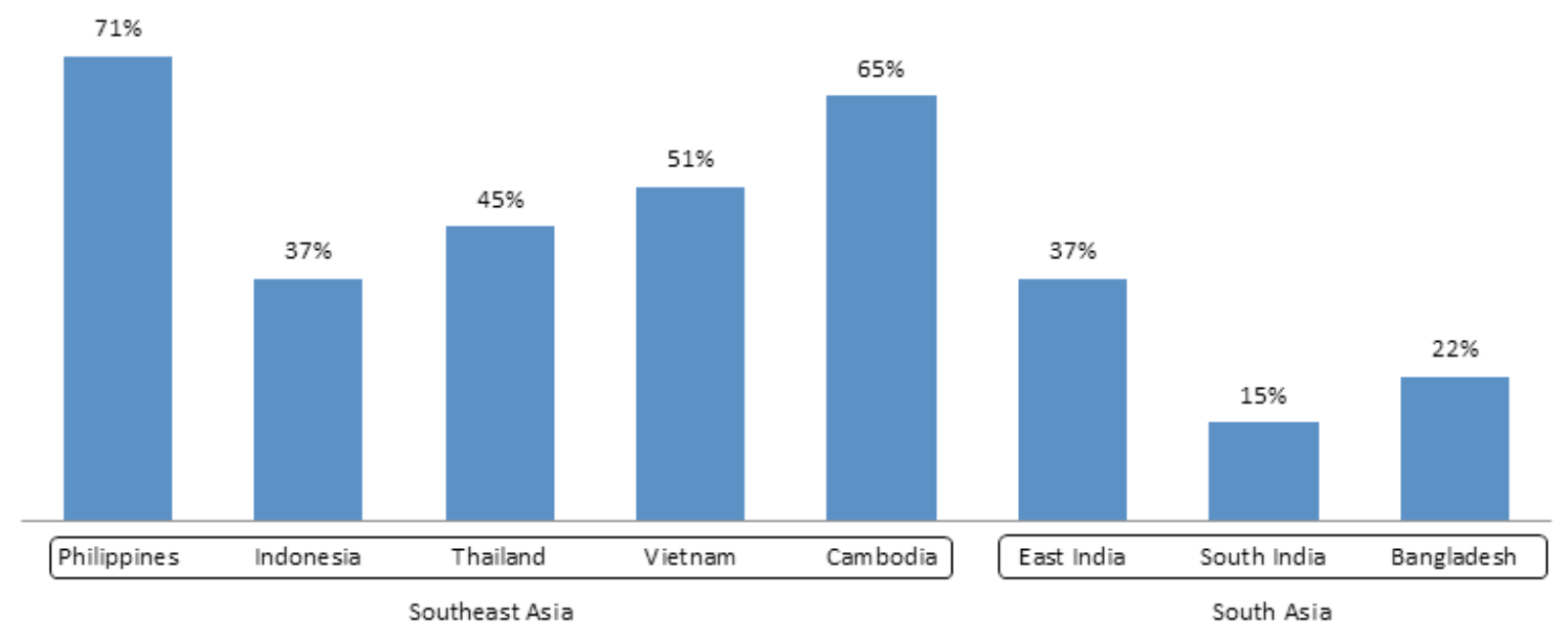

Fig. 3. Proportion of respondents who consider aroma as most preferred rice trait based on consumer surveys in 24 cities in selected South and Southeast Asian countries in 2013-2014. Sample sizes: Philippines $n=500$, Indonesia $n=500$, Thailand $n=500$, Vietnam $n=500$, Cambodia $n=500$, East India $n=803$, South India $n=619$, Bangladesh $n=501$. 

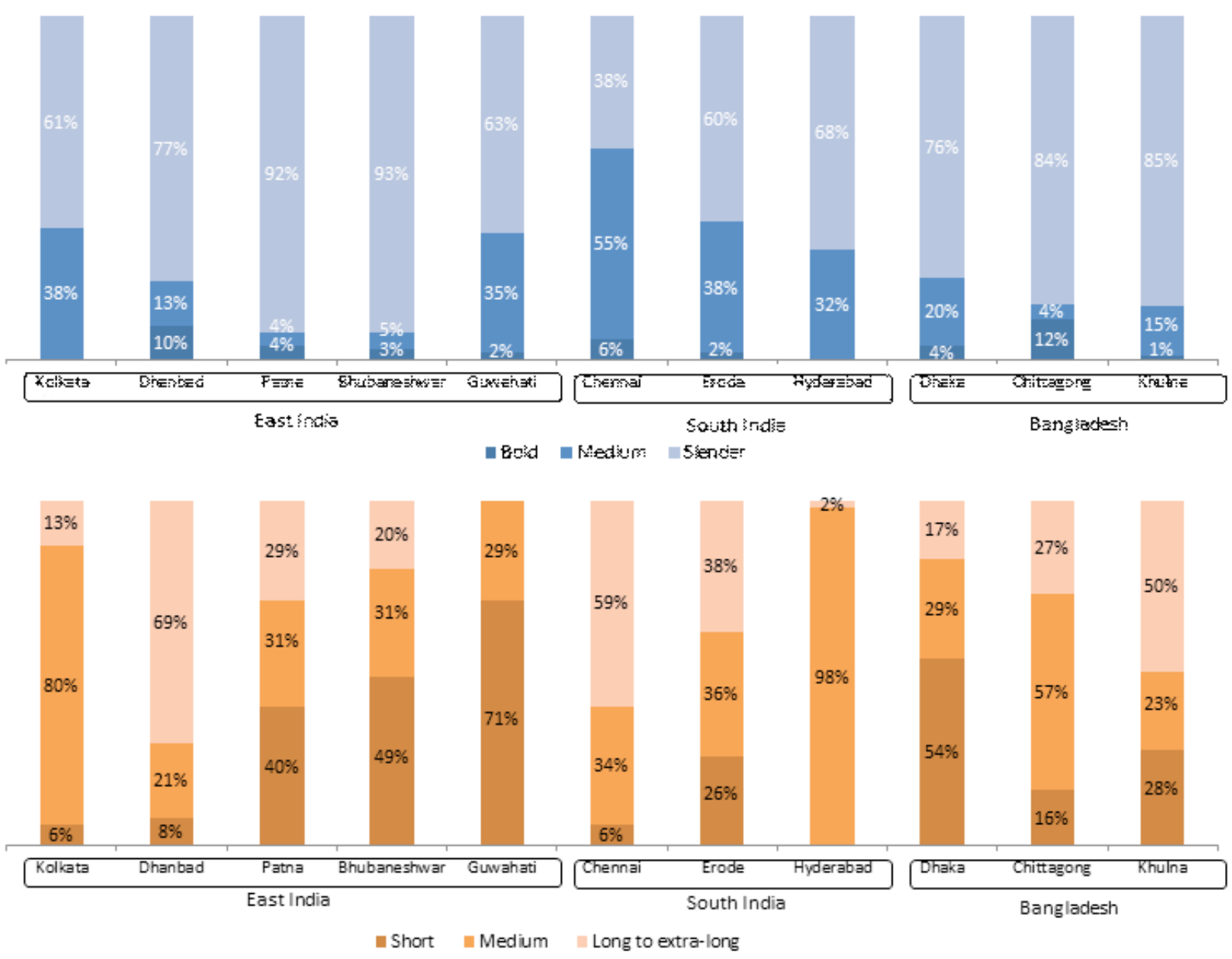

Fig. 4. Preferences for grain shape (upper graph) and grain size (lower graph) of urban consumers who consider respectively shape and size as most preferred rice trait based on consumer surveys in 11 cities in South Asia in 2013-2014. Notes: Sample sizes in upper graph: Kolkata $n=129$, Dhanbad $n=89$, Patna $n=102$, Bhubaneshwar $n=120$, Guwahati $n=24$, Chennai $n=52$, Erode $n=91$, Hyderabad $n=167$, Dhaka $n=128$, Chittagong $n=25$, Khulna $n=27$. Sample sizes in lower graph: Kolkata $n=116$, Dhanbad $n=69$, Patna $n=93$, Bhubaneshwar $n=127$, Guwahati $n=23$, Chennai $n=140$, Erode $n=89$, Hyderabad $n=88$, Dhaka $n=143$, Chittagong $n=28$, Khulna $n=26$. 